\title{
Production of Generalized Learning Deficit and Permanent Growth Stunting by Bilateral Brain Stem Lesions
}

\author{
H. DAVID MOSIER, REGINA A. JANSONS, ROBERT THOMPSON, FRANCIS M. CRINELLA, \\ AND JEN YU \\ Departments of Pediatrics and of Physical Medicine and Rehabilitation, University of California, Irvine, \\ California 92717; and State Developmental Research Institutes, Costa Mesa, California 92626
}

\begin{abstract}
Bilateral lesions of the globus pallidus, ventrolateral thalamus, substantia nigra, or the median raphe produce a generalized learning deficit in rats. Bilateral lesions of the dorsomedial hypothalamic nuclei stunt growth in rats without significantly disturbing endocrine functions and without producing a generalized learning deficit. Globus pallidus, ventrolateral thalamus, substantia nigra, median raphe, and dorsomedial hypothalamic nuclei lesions were produced in weanling Sprague-Dawley rats to compare their effect on physical growth. At approximately $72 \mathrm{~d}$ of age, all lesions had resulted in reduced body wt, tail length, and tibial length. The differences lacked significance only in body wt after median raphe lesions and tail length after ventrolateral thalamus lesions. In rats with the generalized learning deficit, body size was most stunted after substantia nigra lesions. Tibial epiphyseal width was modestly increased in rats with the generalized learning deficit. Food intake/average body wt ratio in substantia nigra and dorsomedial hypothalamic nucleli rats did not differ significantly from control values. Decreases in brain, heart, liver, kidney, and testes tended to occur after all the lesions, but brain and testis organ wt/body wt ratios were either increased or unchanged. We conclude that brain lesions producing a generalized learning deficit in rats result in impaired physical growth. The results indicated that the stunted animals maintain adequate food intake and have normal growth hormone function. The anatomical substrate for generalized learning impairment may overlap with that of a set point for body size. (Pediatr Res 27: 181$185,1990)$
\end{abstract}

Abbreviations

DMH, dorsomedial hypothalamic nuclei

GP, globus pallidus

MR, median raphe

SN, substantia nigra

VLT, ventrolateral thalamus

Young albino rats sustaining discrete bilateral lesions to the GP, VLT, SN, or MR have been reported to be deficient in learning a wide variety of laboratory tasks, including visual and nonvisual discriminations, a three-cul maze, detour problems,

Received September 6, 1988; accepted September 21, 1989.

Correspondence and reprint requests Dr. H. D. Mosier Department of Pediatrics, University of California, Irvine, CA 92717.

Supported by NIH Grant HD 07074 and by funds from the State of California Department of Developmental Services, Developmental Research Institutes. and latch-box habits $(1,2)$. By virtue of this evident generalized learning defect, these young brain-damaged rats have been assumed to be "mentally retarded." This assumption seems reasonably defensible in so far as mentally retarded children also exhibit a generalized learning deficit (3).

We have previously shown that irradiation of only a short narrow midline zone of the head of the neonatal rat resets the animal to a smaller body size (4) without producing major alterations of metabolism or nutrition (5). Lesions of the DMH (6), lateral hypothalamic area (7), nigrostriatal bundle (8), striatum (7), medial forebrain bundle (9), and area postrema/caudal medial nucleus (6) also result in a reduced body size, sometimes with major metabolic and behavioral concomitant disturbances.

Based on the finding that short stature occurs in combination with mental retardation in humans (10), the possibility was considered that areas associated with a generalized learning deficit in the rat may overlap with a set point for body size. In other words, those lesions producing a generalized learning deficit might also reduce body size. Therefore, our study was carried out to determine whether selective lesions to the GP, VLT, SN, and MR would reset the animal to a smaller body size. The growth patterns of rats with bilateral DMH lesions were compared with those of rats with lesions producing a generalized learning deficit to determine whether the effects of and, by inference, the mechanisms involved by the two classes of lesions are similar.

\section{MATERIALS AND METHODS}

Sprague-Dawley rats were obtained from Simonsen Laboratories, Gilroy, CA, at $21-23 \mathrm{~d}$ of age. At $22-28 \mathrm{~d}$ of age surgery was carried out under deep chloral hydrate anesthesia $(400 \mathrm{mg}$ / $\mathrm{kg}$ ). Bilateral electrolytic brain lesions were made stereotaxically with the head of the rat oriented horizontally in the stereotaxic headholder. The coordinates of the GP lesions were $7.0 \mathrm{~mm}$ anterior to $\lambda, 2.7 \mathrm{~mm}$ lateral to the longitudinal sinus, and 5.9 $\mathrm{mm}$ ventral from the surface of the brain. Coordinates of the SN lesions were $3.0 \mathrm{~mm}$ anterior, $2.2 \mathrm{~mm}$ lateral, and $7.2 \mathrm{~mm}$ ventral. Coordinates of the VLT lesions were $5.0 \mathrm{~mm}$ anterior, $2.0 \mathrm{~mm}$ lateral, and $6.0 \mathrm{~mm}$ ventral. Coordinates of the MR lesions were $1.0 \mathrm{~mm}$ anterior, $0 \mathrm{~mm}$ lateral, and $7.5 \mathrm{~mm}$ ventral. Coordinates of the DMH lesions were $4.9 \mathrm{~mm}$ anterior, $0.5 \mathrm{~mm}$ lateral, and $8.0 \mathrm{~mm}$ ventral. Lesions were made by passing a constant anodal current of $1.0-2.0 \mathrm{~mA}$ for a duration of $5-10 \mathrm{~s}$ through an implanted stainless steel electrode $(0.5 \mathrm{~mm}$ in diameter) with $1.0 \mathrm{~mm}$ of the tip exposed. Sham-operated control animals underwent the same surgical procedure as the experimental animals, except for drilling of the skull and insertion of the lesion electrode into the brain. The animals were maintained on a $12 / 12 \mathrm{~h} \mathrm{light/dark} \mathrm{cycle} \mathrm{through} 27 \mathrm{~d}$ of age after which 
the light/dark cycle was $14 / 10$ h. Tap water and Purina Lab Chow (Ralston Purina, St. Louis, MO) were provided ad libitum. Two experiments were carried out. In experiment 1 , the groups were sham operated or lesioned in the GP, SN, MR, and VLT.
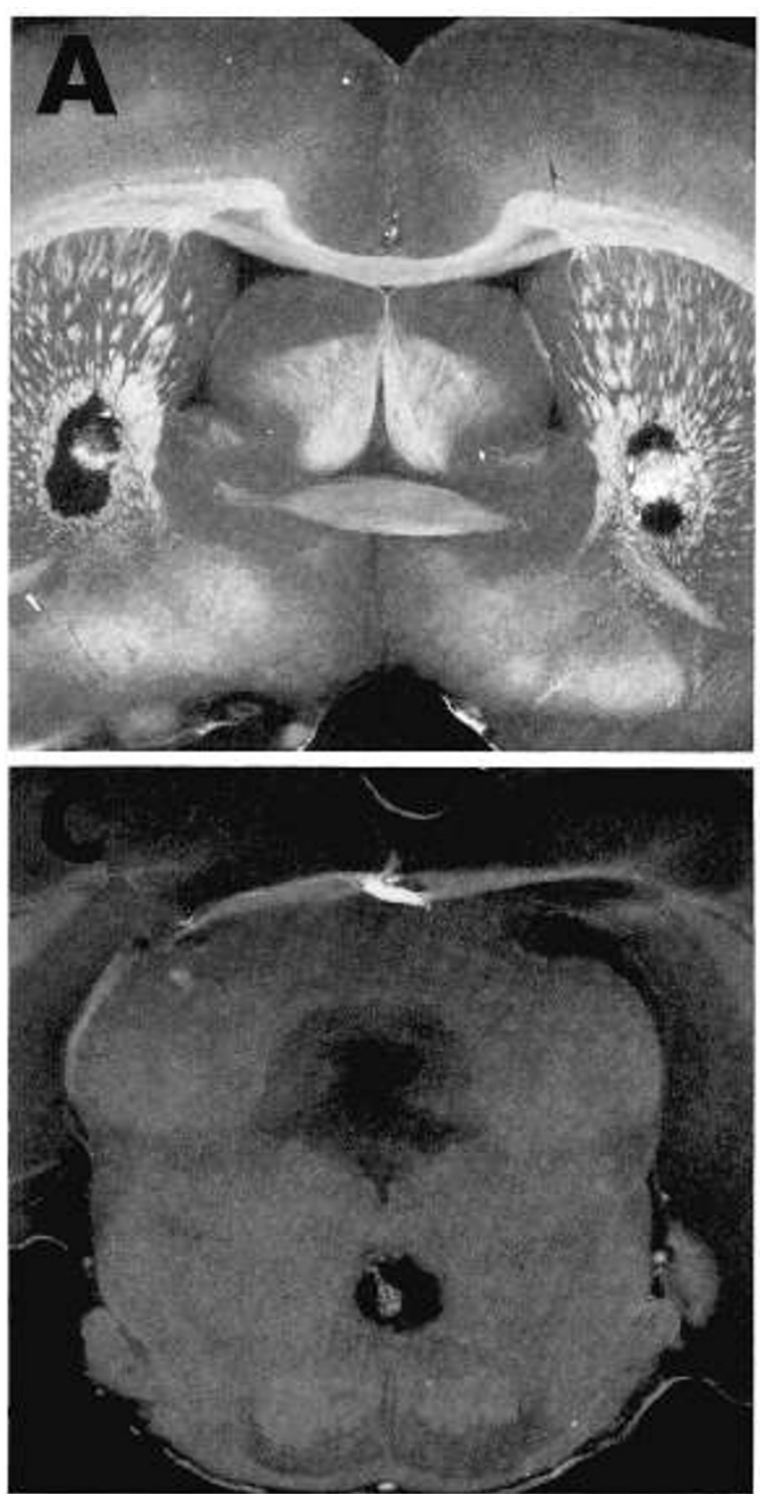

In experiment 2, the groups were sham operated or lesioned in the DMH and SN. In experiment 2, daily food (Purina Lab Chow Meal) intake was measured. In both experiments, measurements of body wt to the nearest $0.1 \mathrm{~g}$ and tail length to the
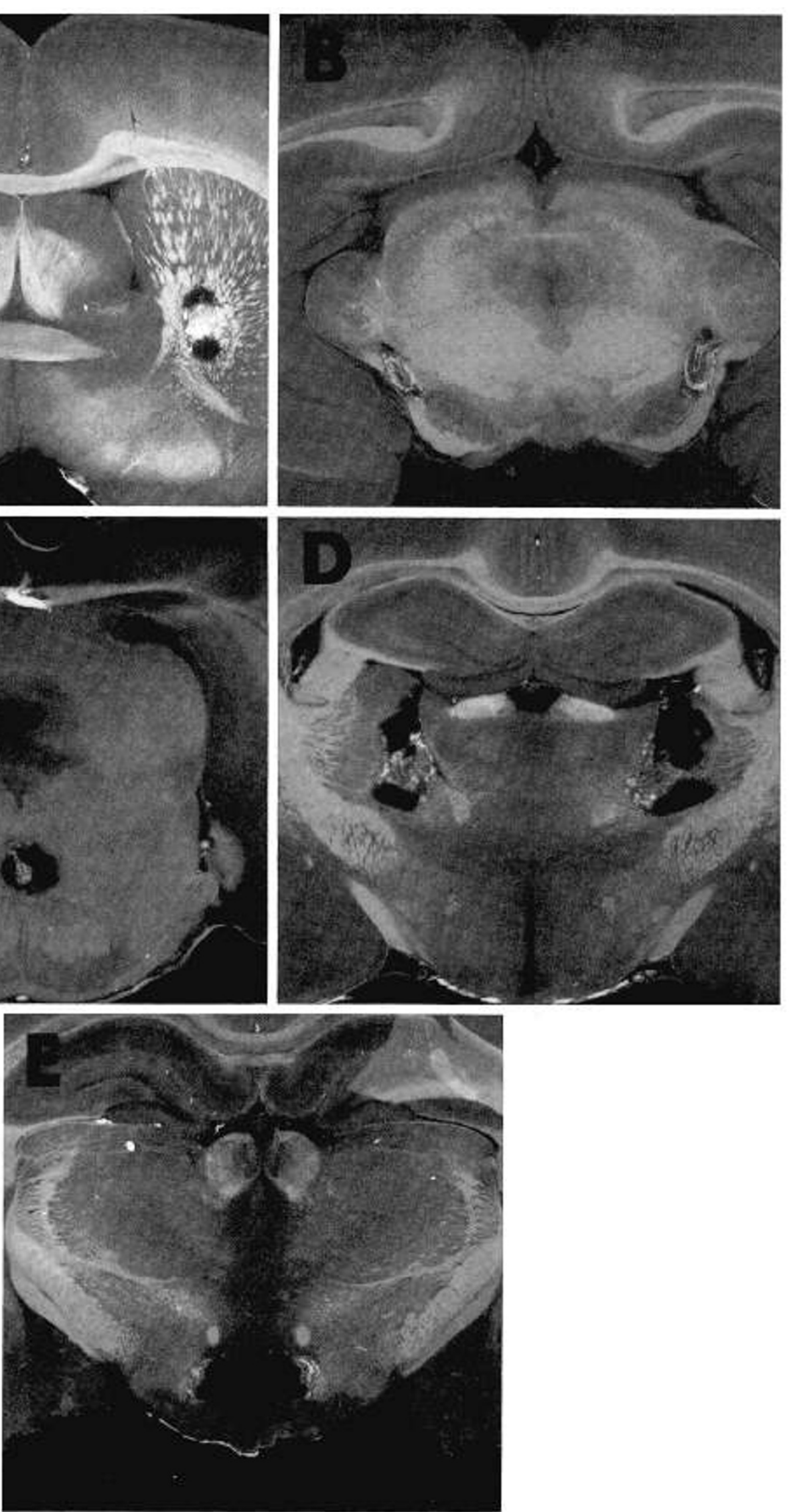

Fig. 1. Unstained sections showing typical lesions. $A, \mathrm{GP} ; B, \mathrm{SN} ; C, \mathrm{MR} ; D$, VLT; $E, \mathrm{DMH}$. 
nearest $0.1 \mathrm{~cm}$ (11) were carried out at weekly intervals from 28 through $73 \mathrm{~d}$ of age. The rats were killed by ether inhalation or decapitation at $73 \mathrm{~d}$ of age in experiment 1 or 71 to $72 \mathrm{~d}$ of age in experiment 2 . Wet wt was determined for brain, heart ventricles, kidneys, liver, and testes. Tibial length was determined to the nearest $0.01 \mathrm{~cm}$. Tibial epiphyseal width was measured by the method of Evans et al. (12). All measurements were done "blindly" with no knowledge as to which groups each subject belonged. Histologic verification of the location of lesions was carried out on frontal frozen sections, as described previously (1). Examples of typical lesion placements are shown in Figure 1 .

Significance of differences between means was determined by $t$ test. $p$ values are two-tailed for tibial epiphyseal width and onetailed for remaining data. The effects of lesions on food intake for average body wt per interval was determined for the entire series of intervals by analysis of variance.

\section{RESULTS}

Discarded Subjects. Eighty-two animals surviving the surgical procedure for 2 to $5 \mathrm{~d}$ were entered into the study. Seven lesioned rats died spontaneously. Two controls and four lesioned rats were killed because they developed severe weakness, reduced body temperature, and poor fur quality. Ten lesioned rats were eliminated because the lesions were unsatisfactory in size, loca- tion, or symmetry. Data from these animals were discarded. All of the animals used for our data had normal muscle tone and vigor, tactile skin temperature, and fur quality.

Food Intake. Food intake/body wt tended to be more than controls after SN lesions and less than controls after DMH lesions, although the differences were significant in only one instance in each group (Table 1). Analysis of variance showed a significant interaction between $\mathrm{SN}$ - and DMH-lesioned rats ( $p$ $<0.05$ ), but not between either of the lesioned groups and the controls.

Histology.The subcortical lesions sustained by the various groups of the current experiment were verified histologically as similar in topography and magnitude to those received by the corresponding groups investigated in the earlier study dealing with the neuroanatomy of mental retardation in the rat (1).

Body Size. Experiment 1. GP, SN, MR, and VLT lesions resulted in a reduction in body wt, tail length, and tibial length. At death the difference was not significant in the case of body wt after MR lesions or tail length after VLT lesions. SN-lesioned rats had the greatest reduction of body wt, tail length, and tibial length of the four lesions (Table 2). Examination of the growth curves showed that animals with $\mathrm{SN}$ lesions tended to have a greater reduction of growth velocity for body wt and tail length than rats with the other lesions.

Experiment 2. Both groups, DMH and $\mathrm{SN}$, had significantly reduced body wt with respect to controls from $28 \mathrm{~d}$ of age. The

Table 1. Average daily food intake (g)/average body wt $(g)$ during measurement interval (data are mean \pm SEM; age is midpoint

\begin{tabular}{|c|c|c|c|c|c|c|}
\hline $\begin{array}{l}\text { Age } \\
\text { (d) }\end{array}$ & $\begin{array}{l}\text { Control } \\
(n=10)\end{array}$ & $\begin{array}{c}\mathrm{DMH} \\
(n=13)\end{array}$ & $p$ & $\begin{array}{c}\mathrm{SN} \\
(n=5)\end{array}$ & $p$ & $p^{*}$ \\
\hline 33.5 & $0.128 \pm 0.005$ & $0.128 \pm 0.003$ & NS & $0.132 \pm 0.007$ & NS & NS \\
\hline 40.5 & $0.113 \pm 0.001$ & $0.111 \pm 0.002$ & NS & $0.115 \pm 0.003$ & NS & NS \\
\hline 47.5 & $0.096 \pm 0.002$ & $0.091 \pm 0.002$ & NS & $0.102 \pm 0.004$ & NS & $<0.025$ \\
\hline 54.5 & $0.088 \pm 0.002$ & $0.081 \pm 0.002$ & $<0.05$ & $0.091 \pm 0.005$ & NS & NS \\
\hline 61.5 & $0.078 \pm 0.002$ & $0.076 \pm 0.002$ & NS & $0.084 \pm 0.005$ & NS & NS \\
\hline 68.5 & $0.072 \pm 0.001$ & $0.072 \pm 0.002$ & NS & $0.082 \pm 0.004$ & $<0.025$ & NS \\
\hline
\end{tabular}

* DMH versus $\mathrm{SN}$.

Table 2. Body wt, tail length, tibial length, and tibial epiphyseal width of lesioned animals and controls (mean \pm SEM)

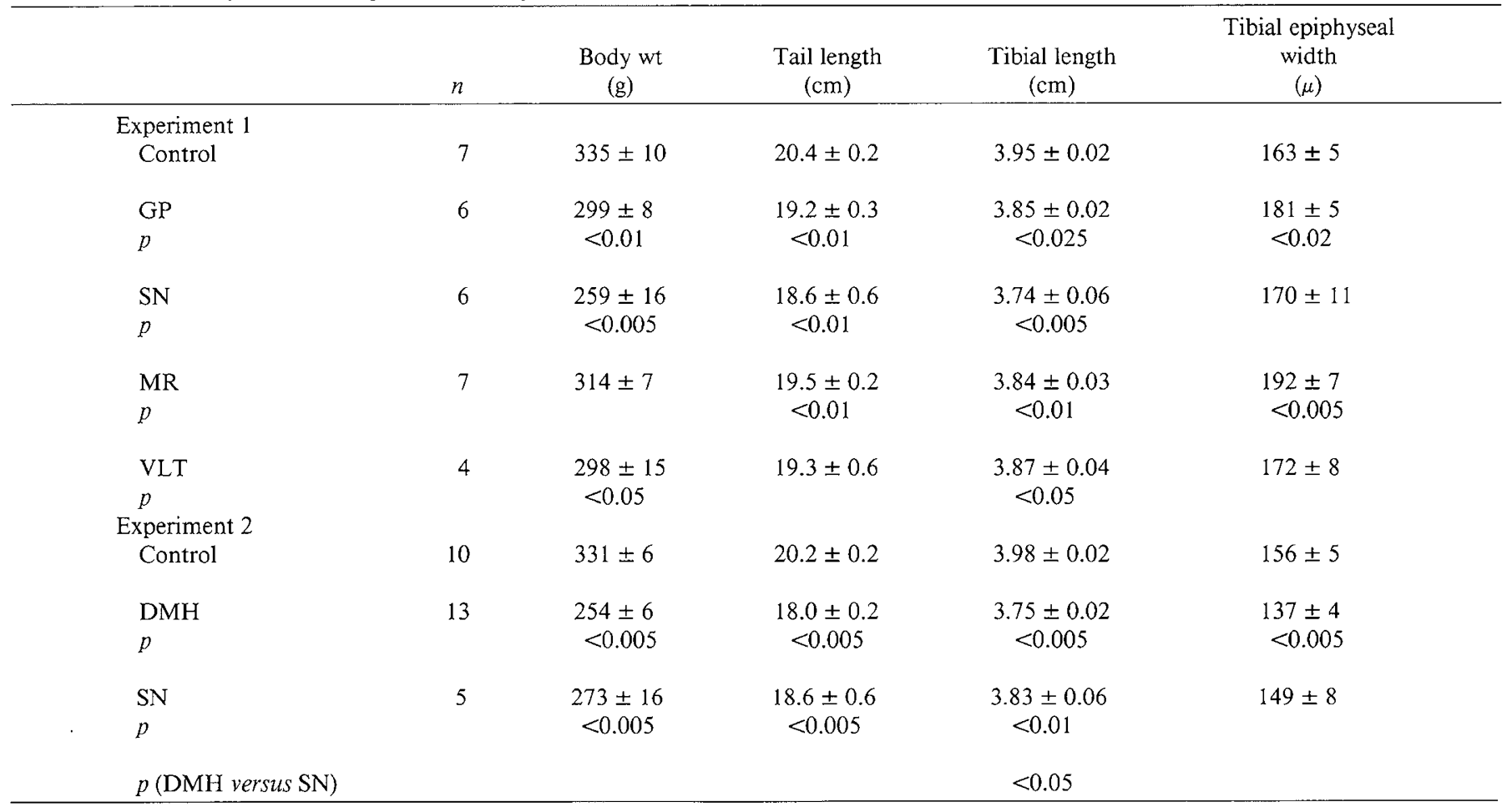


body wt growth curves differed in that the DMH group showed a smooth decline in growth rate from the time of the lesion whereas the SN group tended to have marked retardation early followed by a greater growth rate. Between the ages of 44 and 51 $\mathrm{d}$, the DMH and SN growth curves crossed for both body wt and tail length and $\mathrm{DMH}$ rats remained more stunted than $\mathrm{SN}$ rats throughout the remainder of the experiment. Tail length was significantly reduced from $28 \mathrm{~d}$ of age in the SN group and from $30 \mathrm{~d}$ of age in the DMH group. The DMH and SN groups did not differ significantly from each other at points along the growth curves, possibly because of a smaller sample size and relatively greater variance in the SN data (Fig. 2). Table 2 lists terminal data showing significantly smaller values of body wt, tail length, and tibia length in both groups in comparison to controls. The DMH and SN groups did not differ significantly from each other at the time they were killed with respect to body wt or tail length; however, tibial length was significantly shorter after DMH lesions than after SN lesions.

Tibial Epiphyseal Width. Experiment 1. All lesions resulted in modest increases in tibial epiphyseal width over the control values. These were significant in the case of the GP- and MRlesioned rats (Table 2). Tibial epiphyseal width after SN lesions was not significantly different from the controls or other lesioned groups.

Experiment 2. In $\mathrm{DMH}$ rats, tibial epiphyseal width was reduced significantly. As in experiment 1, there was no change in the SN group.

Organ Weights and Organ/Body Proportions. Experiment 1. Brain wt was significantly reduced after GP, MR, and VLT lesions; no change occurred after MR lesions. Brain/body ratio showed a significant increase in the case of $\mathrm{SN}$ lesions because of the relatively greater decrease of body wt after this lesion. Heart wt was significantly reduced after all lesions except that of the VLT. However, the heart/body ratio was not significantly altered by any of the lesions. There was no significant change in kidney wt after any lesion. Kidney/body ratio was increased after all the lesions reflecting the relative decrease in body wt. This was significantly different after SN and VLT lesions. Liver wt was reduced after all lesions. This was significant for $\mathrm{SN}$ and VLT lesions. However, liver/body ratio was only modestly, but significantly, changed after VLT lesions. Testis wt was reduced significantly after all lesions. Testis/body ratio was not altered significantly except after $\mathrm{SN}$ lesions that resulted in a significant increase in this ratio (Table 3 )

Experiment 2. Weights of brain, heart, liver, kidneys, and testes were reduced in both $\mathrm{DMH}$ and $\mathrm{SN}$ groups. Both groups had increased brain/body and testis/body ratios and a decreased liver/body ratio. The heart/body ratio was unchanged in both groups, as in the groups of experiment 1 . Kidney/body ratio was significantly decreased in the DMH group (Table 3 ).

\section{DISCUSSION}

Our results show that bilateral lesions of four brain stem locations that produce a generalized learning deficit, also produce growth impairment. The greatest growth deficit occurred after $\mathrm{SN}$ lesions. Tibial epiphyseal width was also either normal or increased after lesions of the GP, SN, MR, or VLT; the DMHlesioned animals had a slight, but significant, reduction of tibial epiphyseal width. Dietary measurement in the SN and DMH rats showed no significant alteration of food intake per average body mass.

The tibial epiphyseal width measurements in the rats with generalized learning defects tend to exclude hypopituitarism or undernutrition, either of which would tend to reduce the width $(12,13)$. The possibility that changes occurred in food efficiency for growth and maintenance, cannot be excluded on the basis of our data. However, other findings during the experiments fail to support that possibility. Muscle tone and gross motor activity also appeared normal. We observed no abormality in the consistency of fecal droppings, the amount of hair loss, or of amount and distribution of fat in the carcass. Moreover, it has been shown that after $\mathrm{SN}$ lesions spontaneous activity by the OpenField test does not differ from controls (14).

The occurrence of growth impairment after all of these lesions suggests that the anatomical substrate for generalized learning
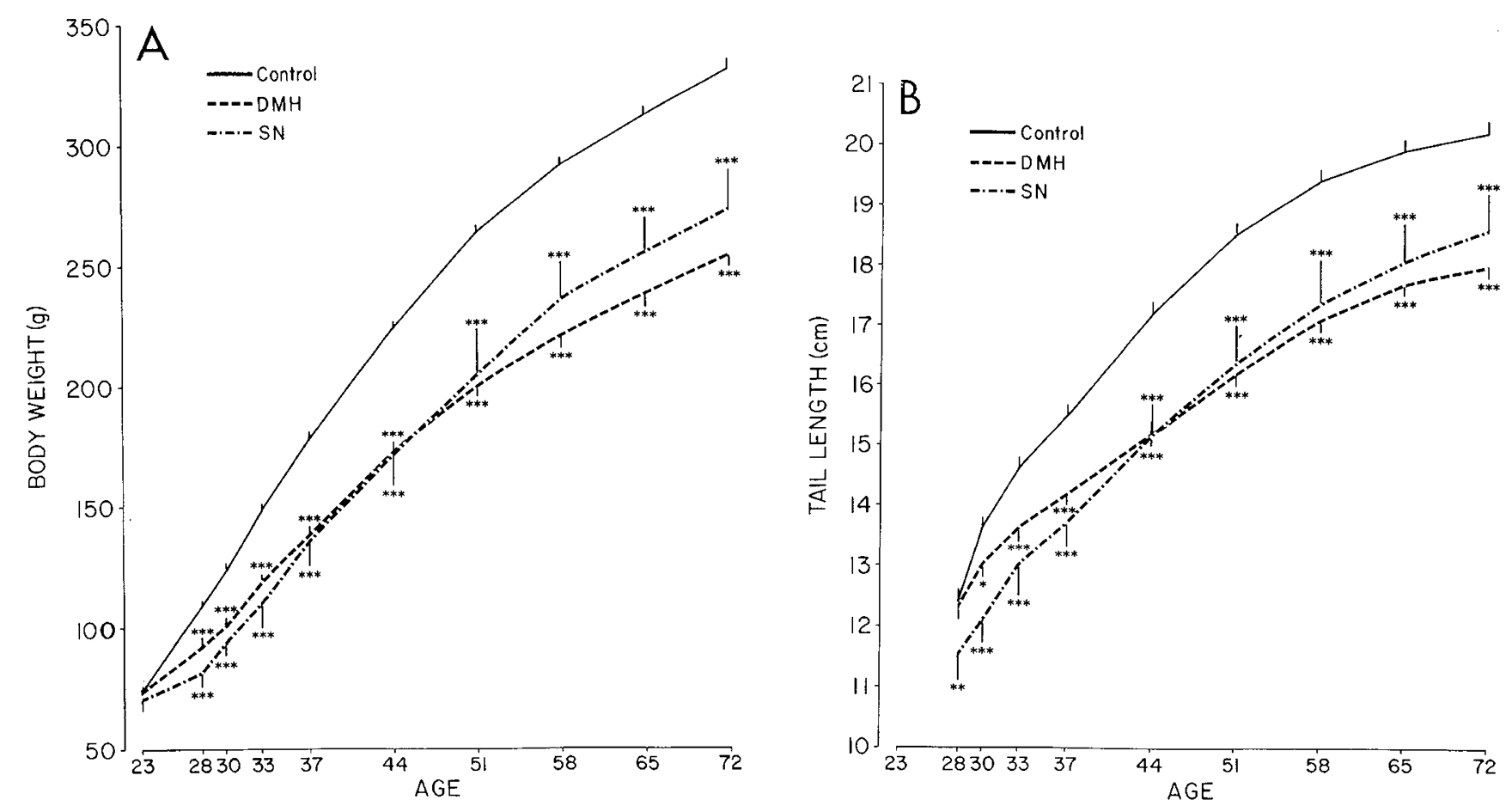

Fig. 2. Growth curves of controls and the DMH and SN groups of experiment 2. $A$, body wt; $B$, tail length. Lesions were performed at $23 \mathrm{~d}$ of age. Tail length data were not obtained at the time of surgery. Wound clips were removed at age $28 \mathrm{~d}$. Data are means \pm SEM at each point. $p$ values are coded as follows: $p<0.05,{ }^{* *} p<0.01,{ }^{* * *} p<0.005$. $\mathrm{N}$ is given in the tables. 
BRAIN STEM LESIONS AND GROWTH

Table 3. Organ wt and organ wt/body wt ratios in lesioned animals and controls (mean $\pm S E M$ )

\begin{tabular}{|c|c|c|c|c|c|c|c|c|c|c|c|}
\hline & $n$ & Brain (g) & $\begin{array}{l}\text { Brain/ } \\
\text { body } \\
(\mathrm{mg} / \mathrm{g})\end{array}$ & $\begin{array}{l}\text { Heart } \\
(\mathrm{g})\end{array}$ & $\begin{array}{l}\text { Heart/ } \\
\text { body } \\
(\mathrm{mg} / \mathrm{g})\end{array}$ & $\begin{array}{l}\text { Liver } \\
(\mathrm{g})\end{array}$ & $\begin{array}{l}\text { Liver/ } \\
\text { body } \\
(\mathrm{mg} / \mathrm{g})\end{array}$ & $\begin{array}{l}\text { Kidneys } \\
(\mathrm{g})\end{array}$ & $\begin{array}{c}\text { Kidney/ } \\
\text { body } \\
(\mathrm{mg} / \mathrm{g})\end{array}$ & $\begin{array}{c}\text { Testes } \\
(\mathrm{g}) \\
\end{array}$ & $\begin{array}{l}\text { Testis/ } \\
\text { body } \\
(\mathrm{mg} / \mathrm{g})\end{array}$ \\
\hline \multicolumn{12}{|c|}{ 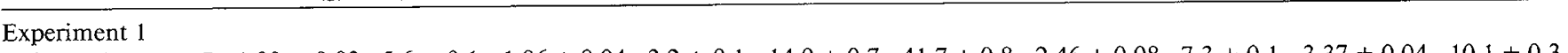 } \\
\hline Control & 7 & $1.89 \pm 0.02$ & $5.6 \pm 0.1$ & $1.06 \pm 0.04$ & $3.2 \pm 0.1$ & $14.0 \pm 0.7$ & $41.7 \pm 0.8$ & $2.46 \pm 0.08$ & $7.3 \pm 0.1$ & $3.37 \pm 0.04$ & $10.1 \pm 0.3$ \\
\hline $\begin{array}{l}\text { GP } \\
p\end{array}$ & 6 & $\begin{array}{l}1.79 \pm 0.02 \\
<0.005\end{array}$ & $\begin{array}{l}6.0 \pm 0.2 \\
<0.05\end{array}$ & $\begin{array}{c}0.92 \pm 0.04 \\
<0.025\end{array}$ & $3.1 \pm 0.1$ & $\begin{array}{l}12.4 \pm 0.4 \\
<0.05\end{array}$ & $41.3 \pm 0.7$ & $2.25 \pm 0.11$ & $7.5 \pm 0.2$ & $\begin{array}{c}3.09 \pm 0.07 \\
<0.005\end{array}$ & $10.3 \pm 0.2$ \\
\hline $\begin{array}{l}\mathrm{SN} \\
p\end{array}$ & 6 & $\begin{array}{c}1.75 \pm 0.00 \\
<0.005\end{array}$ & $\begin{array}{l}6.5 \pm 0.4 \\
<0.01\end{array}$ & $\begin{array}{c}0.83 \pm 0.06 \\
<0.005\end{array}$ & $3.2 \pm 0.1$ & $\begin{array}{c}10.3 \pm 0.8 \\
<0.005\end{array}$ & $39.6 \pm 1.3$ & $\begin{array}{c}2.06 \pm 0.13 \\
<0.025\end{array}$ & $\begin{array}{l}7.9 \pm 0.3 \\
<0.05\end{array}$ & $\begin{array}{l}2.87 \pm 0.12 \\
<0.005\end{array}$ & $\begin{array}{c}11.9 \pm 0.7 \\
<0.025\end{array}$ \\
\hline $\begin{array}{l}\mathrm{MR} \\
p\end{array}$ & 7 & $1.83 \pm 0.03$ & $5.8 \pm 0.1$ & $\begin{array}{l}0.98 \pm 0.02 \\
<0.05\end{array}$ & $3.1 \pm 0.0$ & $13.2 \pm 0.3$ & $42.1 \pm 0.7$ & $2.39 \pm 0.07$ & $7.6 \pm 0.3$ & $\begin{array}{c}3.18 \pm 0.05 \\
<0.025\end{array}$ & $10.1 \pm 0.2$ \\
\hline $\begin{array}{l}\text { VLT } \\
p \\
\text { Experiment } 2\end{array}$ & 4 & $\begin{array}{c}1.73 \pm 0.07 \\
<0.025\end{array}$ & $5.8 \pm 0.2$ & $1.00 \pm 0.06$ & $3.4 \pm 0.1$ & $\begin{array}{c}11.7 \pm 0.7 \\
<0.05\end{array}$ & $\begin{array}{c}39.4 \pm 0.4 \\
<0.05\end{array}$ & $2.35 \pm 0.08$ & $\begin{array}{l}7.9 \pm 0.3 \\
<0.05\end{array}$ & $\begin{array}{c}3.03 \pm 0.17 \\
<0.05\end{array}$ & $10.2 \pm 0.3$ \\
\hline Control & 10 & $1.83 \pm 0.02$ & $5.6 \pm 0.1$ & $1.09 \pm 0.02$ & $3.3 \pm 0.1$ & $14.2 \pm 0.3$ & $43.0 \pm 0.8$ & $2.68 \pm 0.07$ & $8.1 \pm 0.2$ & $3.18 \pm 0.05$ & $9.6 \pm 0.2$ \\
\hline $\begin{array}{l}\mathrm{DMH} \\
p\end{array}$ & 13 & $\begin{array}{c}1.68 \pm 0.01 \\
<0.005\end{array}$ & $\begin{array}{c}6.7 \pm 0.1 \\
<0.005\end{array}$ & $\begin{array}{c}0.79 \pm 0.04 \\
<0.005\end{array}$ & $\begin{array}{c}3.1 \pm 0.1 \\
<0.025\end{array}$ & $\begin{array}{l}9.4 \pm 0.2 \\
<0.005\end{array}$ & $\begin{array}{c}37.1 \pm 0.3 \\
<0.005\end{array}$ & $\begin{array}{c}1.86 \pm 0.05 \\
<0.005\end{array}$ & $\begin{array}{l}7.3 \pm 0.1 \\
<0.005\end{array}$ & $\begin{array}{l}3.04 \pm 0.05 \\
<0.05\end{array}$ & $\begin{array}{c}12.0 \pm 0.2 \\
<0.005\end{array}$ \\
\hline $\begin{array}{l}\mathrm{SN} \\
p\end{array}$ & 5 & $\begin{array}{c}1.75 \pm 0.02 \\
<0.01\end{array}$ & $\begin{array}{c}6.5 \pm 0.4 \\
<0.005\end{array}$ & $\begin{array}{c}0.92 \pm 0.04 \\
<0.005\end{array}$ & $3.4 \pm 0.1$ & $\begin{array}{c}10.4 \pm 0.9 \\
<0.005\end{array}$ & $\begin{array}{c}38.2 \pm 1.5 \\
<0.005\end{array}$ & $\begin{array}{c}2.18 \pm 0.17 \\
<0.005\end{array}$ & $8.0 \pm 0.2$ & $\begin{array}{c}2.99 \pm 0.07 \\
<0.05\end{array}$ & $\begin{array}{c}11.1 \pm 0.6 \\
<0.005\end{array}$ \\
\hline $\begin{array}{c}p \text { (DMH ver- } \\
\text { sus } \mathrm{SN})\end{array}$ & & $<0.025$ & & $<0.01$ & $<0.05$ & & & $<0.025$ & $<0.01$ & & $<0.05$ \\
\hline
\end{tabular}

impairment may overlap with that of a set point for body size. Although it is not established that there is a single or "true" set point for target size, a body of evidence suggests that the DMH may harbor such a mechanism $(7,15)$. The growth curve of the DMH group resembles that of the rats that are stunted by neonatal head-irradiation (16), a lesion that may also reset target size (17). The DMH is richly supplied with connections to neighboring neural structures (18). This is compatible with a key role for the DMH in the response of nervous tissue to humoral blood-borne compounds. It also suggests the possibility of reciprocal effects on the set point by lesions in other areas having connections with the DMH. Thus, the varying degrees of growth impairment and differences in growth curve patterns among these lesions may be related to differing degrees of involvement by particular lesions of the putative set point and of other metabolic and endocrine controls.

\section{REFERENCES}

1. Thompson R, Huestis PW, Crinella FM, Yu J 1986 The neuroanatomy of mental retardation in the white rat. Neurosci Biobehav Rev 10:317-338

2. Thompson R, Bjelajac VM, Huestis PW, Crinella FM, Yu J 1988 Puzzle-box learning impairments in young rats with lesions to the "general learning system." Psychobiology 17:77-88

3. Denny MR 1964 Research in learning and performance. In: Stevens HA, Heber R (eds) Mental Retardation. University of Chicago Press, Chicago, pp $100-142$

4. Mosier HD, Jansons RA 1970 Effect of X-irradiation of selected areas of the head of the newborn rat on growth. Radiat Res 43:92-104

5. Mosier HD, Jansons RA, Swingle KF, Sondhaus CA, Dearden LC, Halsall LC 1985 Growth hormone secretion in the stunted head-irradiated rat. Pediat
Res 19:543-548

6. Bernardis LL, Bellinger LL 1987 The dorsomedial hypothalamic nucleus revisited: 1986 update. Brain Res Rev 12:321-381

7. Van den Pol AN 1982 Lateral hypothalamic damage and body weight regulation: role of gender, diet, and lesion placement. Am J Physiol 242:R265R274

8. Baez LA, Ahlskog E, Randall PK 1977 Body weight and regulatory deficits following unilateral nigrostriatal lesions. Brain Res 132:467-476

9. Levine MS, Hull CD, Fisher RS, Buchwald NA, Heller A 1983 Effects of neonatal destruction of the medial forebrain bundle in the cat: long-term neurochemical, locomotor, and regulatory deficits. Exp Neurol 81:340-358

10. Mosier HD, Grossman HJ, Dingman HF 1965 Physical growth in mental defectives: a study in an institutionalized population. Pediatrics 36(suppl):465-519

11. de Groot DA 1963 Tail growth in the thyroxine-treated hypophysectomized rat as a sensitive criterion for growth hormone activity. Acta Endocrinol $42: 423-431$

12. Evans HM, Simpson ME, Mark W, Kebrick E 1943 Bioassay of the pituitary growth hormone. Width of the proximal epiphyseal cartilage of the tibia in hypophysectomized rats. Endocrinology 32:13-16

13. Shapiro B, Pimstone B 1977 The histology and in vivo sulfate uptake of epiphyseal cartilage in protein-depleted rats. Br J Nutr 38:513-518

14. Thompson R, Harmon D, Yu J 1984 Detour problem-solving behavior in rats with early lesions to the "general learning system." Physiol Psychol 12:193203

15. Bernardis LL, Tannenbaum GS 1987 Failure to demonstrate disruption of ultradian growth hormone rhythm and insulin secretion by dorsomedial hypothalamic nucleus lesions that cause reduced body weight, linear growth and food intake. Exp Brain Res 66:572-576

16. Mosier HD, Jansons RA 1967 Stunted growth in rats following $X$-irradiation of the head. Growth 31:139-148.

17. Mosier HD 1989 Set point for target size in catch-up growth. In: Tanner JM (ed) Auxology 88. Smith-Gordon, London pp 343-351

18. Luiten PGM, Ter Horst GJ, Steffens AB 1987 The hypothalamus, intrinsic connections and outflow pathways to the endocrine system in relation to the control of feeding and metabolism. Prog Neurobiol 28:1-54 